\title{
A desorption mechanism of water following vacuum-ultraviolet irradiation on amorphous solid water at $90 \mathrm{~K}$
}

\section{$\operatorname{AUTHOR}(\mathrm{S}):$}

Hama, Tetsuya; Yokoyama, Masaaki; Yabushita, Akihiro; Kawasaki, Masahiro; Andersson, Stefan; Western, Colin M.; Ashfold, Michael N. R.; Dixon, Richard N.; Watanabe, Naoki

\section{CITATION:}

Hama, Tetsuya ... [et al]. A desorption mechanism of water following vacuum-ultraviolet irradiation on amorphous solid water at 90 K. JOURNAL OF CHEMICAL PHYSICS 2010, 132(16): 164508.

\section{ISSUE DATE:}

2010-04

URL:

http://hdl.handle.net/2433/147191

\section{RIGHT:}

Copyright 2010 American Institute of Physics. This article may be downloaded for personal use only. Any other use requires prior permission of the author and the American Institute of Physics. The following article appeared in JOURNAL OF CHEMICAL PHYSICS132, 164508 (2010) and may be found at http://link.aip.org/link/APPLAB/v96/i23/p233104_s1 


\title{
A desorption mechanism of water following vacuum-ultraviolet irradiation on amorphous solid water at $90 \mathrm{~K}$
}

\author{
Tetsuya Hama, ${ }^{1, a)}$ Masaaki Yokoyama, ${ }^{1}$ Akihiro Yabushita, ${ }^{1}$ Masahiro Kawasaki, ${ }^{1, b)}$ \\ Stefan Andersson, ${ }^{2}$ Colin M. Western, ${ }^{3}$ Michael N. R. Ashfold, ${ }^{3}$ Richard N. Dixon, ${ }^{3}$ and \\ Naoki Watanabe ${ }^{4}$ \\ ${ }^{1}$ Department of Molecular Engineering, Kyoto University, Kyoto 615-8510, Japan \\ ${ }^{2}$ SINTEF Materials and Chemistry, 7465 Trondheim, Norway and Department of Chemistry, Physical \\ Chemistry, University of Gothenburg, 41296 Gothenburg, Sweden \\ ${ }^{3}$ School of Chemistry, University of Bristol, Bristol BS8 1TS, United Kingdom \\ ${ }^{4}$ Institute of Low Temperature Science, Hokkaido University, Sapporo 060-0819, Japan
}

(Received 5 December 2009; accepted 22 March 2010; published online 26 April 2010)

\begin{abstract}
Following $157 \mathrm{~nm}$ photoexcitation of amorphous solid water and polycrystalline water ice, photodesorbed water molecules $\left(\mathrm{H}_{2} \mathrm{O}\right.$ and $\left.\mathrm{D}_{2} \mathrm{O}\right)$, in the ground vibrational state, have been observed using resonance-enhanced multiphoton ionization detection methods. Time-of-flight and rotationally resolved spectra of the photodesorbed water molecules were measured, and the kinetic and internal energy distributions were obtained. The measured energy distributions are in good accord with those predicted by classical molecular dynamics calculations for the kick-out mechanism of a water molecule from the ice surface by a hot hydrogen (deuterium) atom formed by photodissociation of a neighboring water molecule. Desorption of $\mathrm{D}_{2} \mathrm{O}$ following $193 \mathrm{~nm}$ photoirradiation of a $\mathrm{D}_{2} \mathrm{O} / \mathrm{H}_{2} \mathrm{~S}$ mixed ice was also investigated to provide further direct evidence for the operation of a kick-out mechanism. (C) 2010 American Institute of Physics. [doi:10.1063/1.3386577]
\end{abstract}

\section{INTRODUCTION}

In interstellar molecular clouds characterized by dense clumps of material and excess vacuum-ultraviolet (vuv) photons, photoirradiation on dust grains induces desorption of molecules. Photodesorption is often invoked to account for the high gas-phase abundances of less volatile molecules, such as water, that are observed under conditions where complete freeze-out onto dust grains might otherwise be expected. ${ }^{1,2}$ Given the typical size of dust grain and magnitude of vuv flux inside dense molecular clouds, the arrival rate of vuv photons on a dust grain is estimated to be about one photon per day. ${ }^{3,4}$ A proper appreciation of the effects of single UV absorption events is thus likely to be important in developing a realistic picture of photodesorption in dense molecular clouds. Several experimental studies of the photodesorption of water molecules from ice surfaces have been performed. ${ }^{5-9}$ Wolf et al. studied water molecule desorption following $193 \mathrm{~nm}\left(2-40 \mathrm{~mJ} \mathrm{~cm}^{-2}\right)$ irradiation of the water bilayer adsorbed on a $\operatorname{Pd}(111)$ surface, which is due to metal substrate excitations, and reported that the photodesorption became inefficient when water multilayers $(>4 \mathrm{ML})$ were adsorbed. ${ }^{10}$ Öberg et al. ${ }^{11}$ used a vuv lamp emitting in the range of $7.0-10.5 \mathrm{eV}\left(1.1-5.0 \times 10^{13}\right.$ photons $\left.\mathrm{cm}^{-2} \mathrm{~s}^{-1}\right)$ to irradiate ices at surface temperatures of $18-100 \mathrm{~K}$ and detected $\mathrm{H}_{2} \mathrm{O}, \mathrm{OH}, \mathrm{H}_{2}$, and $\mathrm{O}_{2}$ as desorbing species. Molecular dynamics (MD) calculations by Andersson and van Dishoeck $^{3}$ proposed a kick-out mechanism for water photo-

\footnotetext{
${ }^{a)}$ Present address: Institute of Low Temperature Science, Hokkaido University, Sapporo 060-0819, Japan.

b) Author to whom correspondence should be addressed. Electronic mail: kawasaki@moleng.kyoto-u.ac.jp. FAX: +81-75-383-257.
}

desorption following absorption of a single UV photon, i.e., an $\mathrm{H}_{2} \mathrm{O}$ molecule is ejected from the ice by momentum transfer, mainly to the oxygen atom in $\mathrm{H}_{2} \mathrm{O}$, from an energetic $\mathrm{H}$ atom released by photodissociation of a neighboring $\mathrm{H}_{2} \mathrm{O}$, i.e., reactions (1) and (2),

\section{$\Delta H\left(\mathrm{~kJ} \mathrm{~mol}^{-1}\right)$,}

$\mathrm{H}_{2} \mathrm{O}$ (ads or bulk) $\rightarrow$ hot $\mathrm{H}+\mathrm{OH}, \quad$ 541.6,

hot $\mathrm{H}+\mathrm{H}_{2} \mathrm{O}$ (ads) $\rightarrow \mathrm{H}+\mathrm{H}_{2} \mathrm{O}$.

44.5.

In the case of $157 \mathrm{~nm}\left(E_{\text {phot }}=762.0 \mathrm{~kJ} \mathrm{~mol}^{-1}\right)$ photolysis, the excess energy over and above that required for reaction (1), $E_{\text {avail }}(1)$, is $220.4 \mathrm{~kJ} \mathrm{~mol}^{-1}$. Thermodynamic values are calculated using solid or dilute solution phase thermodynamic data for the condensed or adsorbed water ("ads") and gasphase data for other species. ${ }^{12,13}$ We have previously investigated the photodesorption processes of energetic hydrogen atoms and water molecules from both amorphous solid water (ASW) and polycrystalline water ice (PCI) at $90 \mathrm{~K}$ using pulsed 157 or $193 \mathrm{~nm}$ laser radiation, i.e., at wavelengths within the first absorption band of the ice, thereby revealing the translational and internal energy distributions of the photodesorbed species. ${ }^{14-16}$

In the present work, we have performed (a) an experimental study of photodesorption mechanisms and dynamics of water molecules from ASW and PCI at $90 \mathrm{~K}$ seeking evidence for the operation of the kick-out mechanism, i.e., reaction (2), and (b) classical MD calculations of the translational and rotational energies of photodesorbed $\mathrm{H}_{2} \mathrm{O}$ molecules from an ASW ice surface. 


\section{EXPERIMENTAL}

\section{A. Apparatus and preparation of ice}

The apparatus has been described before,${ }^{17}$ and only details relevant to the present experiments are given here. A vacuum chamber was evacuated to a base pressure of $10^{-8}$ Torr using two turbo-molecular pumps in tandem (Shimadzu, 800 and $501 \mathrm{~s}^{-1}$ ). An optically flat sapphire disk substrate, sputter coated with a thin polycrystalline film of $\mathrm{Au}(111)$, was supported in the center of the chamber by a liquid-nitrogen-cooled manipulator connected to an X-Y-Z stage. ${ }^{18}$ The temperature of the substrate was controlled to within $1 \mathrm{~K}$.

Three types of ice samples were prepared: amorphous solid $\mathrm{H}_{2} \mathrm{O}$ and $\mathrm{D}_{2} \mathrm{O}$ water ices [henceforth termed $\operatorname{ASW}\left(\mathrm{H}_{2} \mathrm{O}\right)$ and $\operatorname{ASW}\left(\mathrm{D}_{2} \mathrm{O}\right)$, respectively], polycrystalline $\mathrm{H}_{2} \mathrm{O}$ water ice $\left(\mathrm{PCI}\left(\mathrm{H}_{2} \mathrm{O}\right)\right)$, and a $\mathrm{D}_{2} \mathrm{O}$ ice sample containing an $\mathrm{H}_{2} \mathrm{~S}$ ice interlayer. ASW were prepared by backfilling deposition of water vapor onto the polycrystalline gold substrate at $90 \mathrm{~K}$ for $60 \mathrm{~min}$. The chamber pressure was 5 $\times 10^{-7}$ Torr during the deposition. $\mathrm{PCI}\left(\mathrm{H}_{2} \mathrm{O}\right)$ samples were prepared by deposition of background $\mathrm{H}_{2} \mathrm{O}$ vapor at $130 \mathrm{~K}$ for $60 \mathrm{~min}$ and then further maintaining the ice at $130 \mathrm{~K}$ for $30 \mathrm{~min}$ for annealing purposes. The prepared $\mathrm{PCI}\left(\mathrm{H}_{2} \mathrm{O}\right)$ may have both cubic and hexagonal structures. Its surface is partially disordered due to grain boundaries. ${ }^{17}$ Since time-offlight (TOF) spectra of the photofragment hydrogen atoms following $193 \mathrm{~nm}$ photolysis of water molecules on ice surface strongly depend on surface morphology, ${ }^{14,15}$ the morphology of the prepared PCI surface was confirmed by observing the TOF spectrum of the photofragment hydrogen atoms. Details of the characteristics of prepared ASW and PCI have been discussed in our previous publications. ${ }^{14,15,17}$

To obtain the nascent internal and kinetic energy distributions of photodesorbed water molecules without the influence of the ice/gold interface, we performed thick-iceexperiments. The water vapor exposure was typically $1500 \mathrm{~L}$ ( $1 \mathrm{~L}=1 \times 10^{-6}$ Torr $\left.\mathrm{s}\right)$. This exposure resulted in formation of roughly $500 \mathrm{ML}$ of $\mathrm{H}_{2} \mathrm{O}$ (or $\mathrm{D}_{2} \mathrm{O}$ ) on the substrate if we adopt the reported experimental conversion factor of $1 \mathrm{ML}$ deposition by $3 \mathrm{~L}$ exposure, ${ }^{19}$ which are expected to be sufficiently thick to negate the possible influence of reactions at the ice/gold substrate interface and of any photoelectrons from the gold substrate. ${ }^{10,20-22}$

For the $\mathrm{D}_{2} \mathrm{O}: \mathrm{H}_{2} \mathrm{~S}$ mixed ice sample, the $\operatorname{ASW}\left(\mathrm{D}_{2} \mathrm{O}\right)$ was exposed to a mixture of $\mathrm{H}_{2} \mathrm{~S}(30 \%)+\mathrm{N}_{2}(70 \%)$ gas. The $\mathrm{H}_{2} \mathrm{~S}$ exposure was $\sim 80 \mathrm{~L}$ for $10 \mathrm{~min}$ duration at $90 \mathrm{~K}$. After $\mathrm{H}_{2} \mathrm{~S}$ deposition, $\mathrm{D}_{2} \mathrm{O}$ (10-70 L) was further deposited on the $\mathrm{H}_{2} \mathrm{~S}$ layer.

Unfocused $\mathrm{F}_{2}$ excimer laser (Lambda Physik, OPTexPro, Göttingen, Germany) radiation at $157 \mathrm{~nm}$ with a pulse duration of $10 \mathrm{~ns}$ was incident on the ice surface at an angle of $\sim 80^{\circ}$ to the surface normal and at a fluence, $F<0.1 \mathrm{~mJ} \mathrm{~cm}^{-2}\left(\sim 10^{14}\right.$ photons cm $\mathrm{cm}^{-2}$ pulse $\left.{ }^{-1}\right)$; the corresponding fluence when using an $\mathrm{ArF}$ excimer laser (Lambda Physik, COMPex) at $193 \mathrm{~nm}$ was $F<1.0 \mathrm{~mJ}$ $\mathrm{cm}^{-2}\left(\sim 10^{15}\right.$ photons $\mathrm{cm}^{-2}$ pulse $\left.{ }^{-1}\right)$. Although Yabushita et al. previously observed hydrogen atom photofragments following $193 \mathrm{~nm}$ photodissociation of ASW and PCI, ${ }^{14,15} 193$
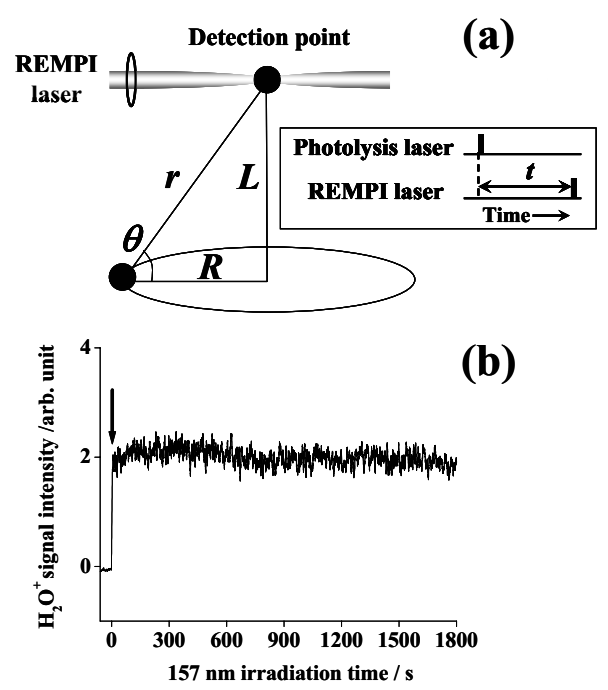

FIG. 1. (a) Schematic illustration of the experiment. Desorbed water molecules following $157 \mathrm{~nm}$ photoirradiation on ice samples are detected by the REMPI technique. The timing plot for measurements of a TOF spectrum is also shown where the delay time, $t$, between photolysis and probe laser pulses corresponds to the TOF. A ellipse indicates an irradiation area on the substrate. $L(=2 \mathrm{~mm})$ is the vertical distance between the substrate and the detection point. $R(=6 \mathrm{~mm})$ is the radius of the irradiation area. $r$ is the effective flight distance to the REMPI probe region given by $r=\left(L^{2}+R^{2}\right)^{1 / 2}$. $\theta$ is the surface polar coordinate. (b) Time evolution curve of the $\mathrm{H}_{2} \mathrm{O}(v=0)$ REMPI signal measured via the $22_{02}-3_{21}$ line of the $C-X 0_{0}^{0}$ transition, as a function of irradiation time at $157 \mathrm{~nm}$ at fixed delay $t=2.5 \mu \mathrm{s}$. The arrow indicates the time at which $157 \mathrm{~nm}$ irradiation starts.

nm irradiation of $\mathrm{ASW}\left(\mathrm{H}_{2} \mathrm{O}\right.$ or $\left.\mathrm{D}_{2} \mathrm{O}\right)$ resulted in no measurable $\mathrm{H}_{2} \mathrm{O}$ or $\mathrm{D}_{2} \mathrm{O}$ resonance-enhanced multiphoton ionization (REMPI) signal in such thick condensed ice and weak $193 \mathrm{~nm}$ laser intensity, which is consistent with the previously reported experimental study by Wolf $e t a l .^{10}$

The photoirradiated area in all cases was a disk of radius $6 \mathrm{~mm}$. As shown in Fig. 1(a), photodesorbed $\mathrm{H}_{2} \mathrm{O}$ and $\mathrm{D}_{2} \mathrm{O}$ molecules were detected by $2+1$ REMPI via the $C(000)$ $-X(000)$ transition, at wavelengths in the range of 247.5$248.5 \mathrm{~nm}$ produced by frequency doubling the output of a $\mathrm{Nd}^{3+}$ :YAG pumped dye laser (Lambda Physik, SCANmate) and collected with a small mass spectrometer aligned perpendicularly to the ice surface.

\section{B. Simulation of $2+1$ REMPI spectra of water molecules}

PGOPHER, a program for simulating the rotational structure accompanying one- and multiphoton electronic transitions, ${ }^{23}$ was used to simulate the measured $2+1$ REMPI spectra and thereby establish best-fit values of the rotational temperatures of the water products. Spectroscopic parameters for the ground and excited state levels of $\mathrm{H}_{2} \mathrm{O}$ and $\mathrm{D}_{2} \mathrm{O}$ were taken from the literature, ${ }^{24}$ including a recent reexamination of the two photon spectra. The simulation included the effect of excited state predissociation, as discussed in the cited works, which gives a predissociation rate that scales broadly with $\left\langle K_{\mathrm{a}}{ }^{2}\right\rangle$, i.e., with the expectation value of square of the rotational angular momentum about the $a$-axis in the $C$ state level of interest. The simulations only included the origin band of the $C-X$ transition and gave a reasonably good fit to the spectra. 
Relatively little information is available on vibrationally excited states of the $C$ state, ${ }^{25}$ but given the similar geometry of the Rydberg and ground states of water, we would expect any vibrationally excited states to give the strongest spectra in the same region as the origin band. The good fit to ground state only spectra suggests little vibrational excitation in the $\mathrm{H}_{2} \mathrm{O}$ and $\mathrm{D}_{2} \mathrm{O}$ products, though we note that Uselman et al. ${ }^{25}$ suggested an increasing degree of predissociation for higher $C$ state vibrational states, which would make the states harder to detect for increasing vibrational energy, and our detection method is probably completely insensitive to molecules with a large degree of vibrational or rotational excitation.

The spin temperature was taken to be the same as the rotational temperature for both $\mathrm{H}_{2} \mathrm{O}$ and $\mathrm{D}_{2} \mathrm{O}$. There is some discussion (see, for example, Bonev et al. ${ }^{26}$ ) on the question of whether spin temperatures in comets are always in equilibrium, though note that for all the temperatures used here $(>50 \mathrm{~K})$, the ortho:para ratios are essentially the statistical values of 3:1 for $\mathrm{H}_{2} \mathrm{O}$ and 2:1 for $\mathrm{D}_{2} \mathrm{O}$. A lower temperature experiment would be necessary to probe any nuclear spin state selectivity.

\section{Simulation of TOF spectra of desorbed water molecule}

TOF spectra of photoproducts were taken as a function of time, $t$, between the photolysis and REMPI laser pulses using a delay generator (Stanford Research) in order to investigate the translational energies of the desorbing photoproducts as shown schematically in Fig. 1(a). The measured TOF spectra, $S\left(t, T_{\text {trans }}\right)$, were fitted to a Maxwell-Boltzmann (MB) distribution, $S_{\mathrm{MB}}$, defined by a translational temperature, $T_{\text {trans }}$. Details regarding the simulation of such TOF spectra in terms of Eq. (3) have been reported previously, ${ }^{17}$

$$
S_{\mathrm{MB}}\left(t, T_{\text {trans }}\right)=r^{3} t^{-4} \exp \left[-m r^{2} / 2 k_{\mathrm{B}} T_{\text {trans }} t^{2}\right],
$$

where $r$ is the flight distance to the REMPI probe region given by $r=\left(L^{2}+R^{2}\right)^{1 / 2}$ as shown in Fig. 1(a). In these calculations we assume that signals come from a disk (vuv photoirradiation area) with a radius of $6 \mathrm{~mm}$, and the detection probability is proportional to $2 \pi R \mathrm{~d} R /\left(L^{2}+R^{2}\right)$, where $L(=2 \mathrm{~mm})$ is a vertical flight distance and $R(0 \leq R$ $\leq 6 \mathrm{~mm})$ is the radius of the irradiation area. The MB distribution, $P_{\mathrm{MB}}\left(E_{t}\right)$, as a function of translational energy, $E_{t}$, is characterized by the averaged translational energy, $\left\langle E_{t}\right\rangle$ $=2 k_{\mathrm{B}} T_{\text {trans }}$, where $k_{\mathrm{B}}$ is the Boltzmann constant, ${ }^{27}$

$$
P_{\mathrm{MB}}\left(E_{t}\right)=\left(k_{\mathrm{B}} T_{\text {trans }}\right)^{-2} E_{t} \exp \left[-E_{t} / k_{\mathrm{B}} T_{\text {trans }}\right] .
$$

Conversion from the $E_{t}$ distribution to the TOF distribution was performed using the Jacobian given by Zimmerman and Ho. ${ }^{28}$ The angular distribution of the molecules photodesorbed from the ice surface was assumed to follow a $\cos ^{n} \theta$ function, where $\theta$ is the surface polar coordinate. $n=0$ was adopted in the best-fitting procedures. ${ }^{17,29}$

\section{MD calculation method}

All our calculations have been performed using classical MD methods ${ }^{30}$ with analytical potentials. Details of the com- putational procedure have been described in the work of Andersson et al. ${ }^{3,31}$ Here, only a brief outline of the methods will be presented.

\section{Amorphous water ice}

To create an amorphous ice slab, the procedure outlined in the work of Al-Halabi $e t$ al. ${ }^{32}$ was used. In brief, a slab of eight bilayers (16 monolayers) of crystalline ice was first created consisting of a cell containing 480 molecules. After the transition to amorphous ice, the resulting amorphous ice structure most closely resembles the structure of compact amorphous ice obtained experimentally and is thought to be representative of the structure of interstellar water ice. . $^{3,33}$

\section{Initial conditions}

Once the ice surface is set up, one $\mathrm{H}_{2} \mathrm{O}$ molecule is chosen to be photodissociated. This molecule is then made completely flexible, and its intramolecular (internal) interactions are governed by an analytic potential energy surface for the first electronically excited state (the $A{ }^{1} \mathrm{~B}_{1}$ state) of gasphase $\mathrm{H}_{2} \mathrm{O}$ based on high-quality $a b$ initio electronic structure calculations. ${ }^{34}$ This excited potential is fully repulsive so that absorption into this state leads to dissociation of the $\mathrm{H}_{2} \mathrm{O}$ molecule into $\mathrm{H}+\mathrm{OH}$. Dissociation of molecules in the top three monolayers has been considered. For each monolayer all 30 molecules have been dissociated, one molecule at a time. For each molecule 10000 configurations and momenta were sampled from a Wigner distribution of the vibrational ground state of $\mathrm{H}_{2} \mathrm{O}$. To reproduce the experimental conditions most closely, only those configurations that correspond to excitation energies in the range of 7.8-8.0 eV (155-159 $\mathrm{nm}$ ) were chosen as initial conditions for the trajectories. Out of the initial 900000 configurations, about 70000 were in this range and were used for the dynamics calculations.

\section{Dynamics of the dissociating molecule}

After putting the molecule in the excited state, the dissociating trajectory is integrated with a time step of $0.02 \mathrm{fs}$. A maximum time of $20 \mathrm{ps}$ has been used before terminating the trajectory. Most of the trajectories $(99.5 \%)$ were terminated before that because the system was found in one of the final outcomes with negligible probability of transforming into a different state. When the excited $\mathrm{H}_{2} \mathrm{O}$ dissociates, the intermolecular interactions are smoothly switched into separate interactions between the photoproducts and water ice, i.e., $\mathrm{H}-\mathrm{H}_{2} \mathrm{O}$ and $\mathrm{OH}-\mathrm{H}_{2} \mathrm{O}$ potentials. All details of the potentials and the functions used to switch between different potentials are given in Andersson et al. ${ }^{31}$ The switching functions connect the partial charges, the dispersion interactions and repulsive potentials between the $\mathrm{H}_{2} \mathrm{O}-\mathrm{H}_{2} \mathrm{O}$ potentials and the $\mathrm{OH}-\mathrm{H}_{2} \mathrm{O}$ and $\mathrm{H}-\mathrm{H}_{2} \mathrm{O}$ potentials affecting the dissociating molecule. 


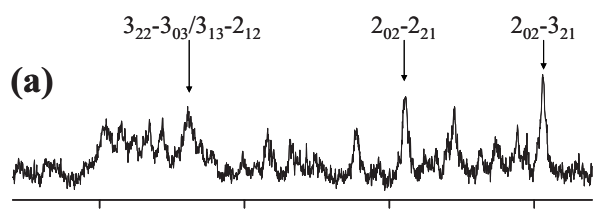

(b)

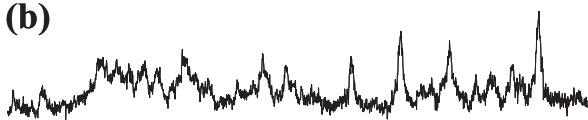

(c)

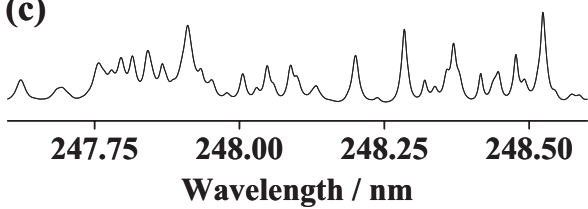

FIG. 2. (a) $2+1$ REMPI spectrum of $\mathrm{H}_{2} \mathrm{O}(v=0)$ formed by $157 \mathrm{~nm}$ photoirradiation of $\mathrm{ASW}\left(\mathrm{H}_{2} \mathrm{O}\right)$ at $90 \mathrm{~K}$, measured at $t=2.5 \mu \mathrm{s}$. The arrows indicate wavelengths at which TOF spectra were measured for Fig. 3. (b). REMPI spectrum from $\mathrm{PCI}\left(\mathrm{H}_{2} \mathrm{O}\right)$ at $90 \mathrm{~K}$. (c) Simulation of the $\mathrm{H}_{2} \mathrm{O}, C-X, 0_{0}^{0}$ two-photon spectrum, assuming a Boltzmann rotational state population distribution with $T_{\text {rot }}=350 \mathrm{~K}$ and $g_{\mathrm{OPR}}=3$.

\section{EXPERIMENTAL RESULTS}

\section{A. Photodesorption of $\mathrm{H}_{2} \mathrm{O}$ following $157 \mathrm{~nm}$ photoirradiation of $\mathrm{ASW}\left(\mathrm{H}_{2} \mathrm{O}\right)$}

Figure 2(a) shows a rotationally resolved REMPI spectrum of $\mathrm{H}_{2} \mathrm{O}(v=0)$ molecules observed following $157 \mathrm{~nm}$ photoirradiation of $\mathrm{ASW}\left(\mathrm{H}_{2} \mathrm{O}\right)$ at $90 \mathrm{~K}$ and a fixed delay time, $t=2.5 \mu \mathrm{s}$. The best-fit simulation obtained using the appropriate two-photon rotational line strengths and widths given the previously reported rotational level dependent predissociation of the $C(v=0)$ state is shown in Fig. 2(c). By comparison with spectral simulation, the rotational temperature, $T_{\text {rot }}$, is determined as $350 \pm 150 \mathrm{~K} \quad\left(\left\langle E_{\text {rot }}\right\rangle\right.$ $\left.=4.4 \pm 1.9 \mathrm{~kJ} \mathrm{~mol}^{-1}\right)$ and the ortho:para ratio, $g_{\mathrm{OPR}}$, estimated to be 3 [which is the statistical equilibrium value above $\sim 60 \mathrm{~K}$ (Ref. 26)].

Figure 3(a) shows a TOF spectrum of $\mathrm{H}_{2} \mathrm{O}(v=0)$ measured when exciting the $2_{02}-3_{21}$ line of the $C-X$ origin band at $248.514 \mathrm{~nm}$, which is reproduced well by a MB distribution with $T_{\text {trans }}=1800 \pm 500 \mathrm{~K} \quad\left(\left\langle E_{\text {trans }}\right\rangle\right.$ $\left.=29.9 \pm 8.3 \mathrm{~kJ} \mathrm{~mol}^{-1}\right)$. Changing the probe wavelength to excite other transitions, e.g., the $C-X, 0_{0}^{0}, 2_{02}-2_{21}$ line or the blended $3_{22}-3_{03} / 3_{13}-2_{12}$ lines, caused no discernible change in the TOF profiles. Table I summarizes these results. Figure (b) shows the time evolution of the $\mathrm{H}_{2} \mathrm{O}, \mathrm{C}-\mathrm{X}, 0_{0}^{0}, 2_{02}-3_{21}$ line intensity as a function of duration of the $157 \mathrm{~nm}$ irradiation. The signal appeared promptly and remained constant during $30 \mathrm{~min}$ of subsequent irradiation.

$157 \mathrm{~nm}$ irradiation of $\mathrm{PCI}\left(\mathrm{H}_{2} \mathrm{O}\right)$ yielded REMPI and TOF spectra of $\mathrm{H}_{2} \mathrm{O}(v=0)$ that were essentially identical both in intensity and profile to those obtained from the ASW sample as shown in Figs. 2(b) and 3(b). $T_{\text {rot }}$ is estimated to be $350 \pm 150 \mathrm{~K} \quad\left(\left\langle E_{\mathrm{rot}}\right\rangle=4.4 \pm 1.9 \mathrm{~kJ} \mathrm{~mol}^{-1}\right)$ from the REMPI spectrum [Figs. 2(b) and 2(c)], and a TOF spectrum obtained when exciting the $2_{02}-3_{21}$ line of the REMPI spectrum is reproduced with $T_{\text {trans }}=1600 \pm 500 \mathrm{~K} \quad\left(\left\langle E_{\text {trans }}\right\rangle\right.$ $=26.6 \pm 8.3 \mathrm{~kJ} \mathrm{~mol}^{-1}$ ) [Fig. 3(b)]. The temporal evolution of

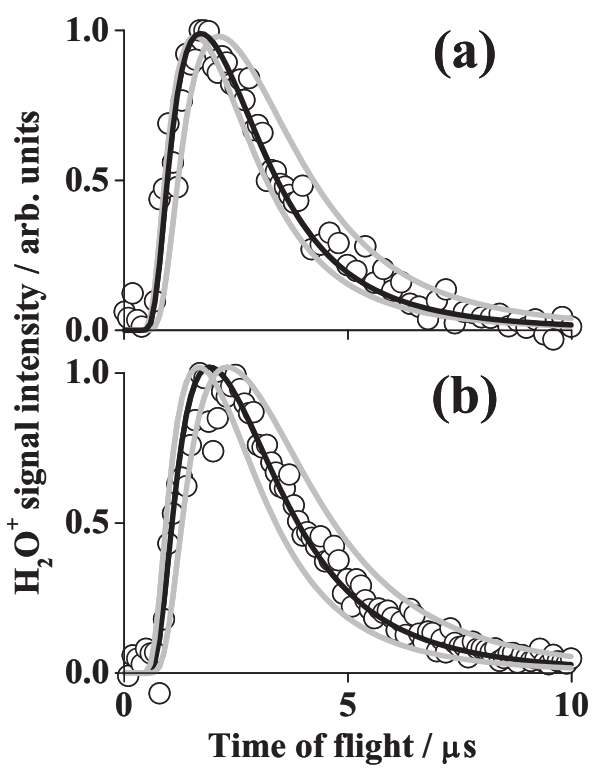

FIG. 3. (a) TOF spectrum of $\mathrm{H}_{2} \mathrm{O}(v=0)$ formed by $157 \mathrm{~nm}$ photoirradiation of $\mathrm{ASW}\left(\mathrm{H}_{2} \mathrm{O}\right)$ at $90 \mathrm{~K}$, monitored via the $2_{02}-3_{21}$ line of the $C-X 0_{0}^{0}$ twophoton transition. The solid curve is a fit to the data derived assuming a MB distribution with $T_{\text {trans }}=1800 \mathrm{~K}$. (b) TOF spectrum of $\mathrm{H}_{2} \mathrm{O}(v=0)$ from $\mathrm{PCI}\left(\mathrm{H}_{2} \mathrm{O}\right)$ at $90 \mathrm{~K}$, monitored via the same line with the case of $\mathrm{ASW}\left(\mathrm{H}_{2} \mathrm{O}\right)$. The solid curve is a fit to the data derived assuming $T_{\text {trans }}=1600 \mathrm{~K}$. The two gray curves show the range spanned by the error bars quoted in Table I.

the $\mathrm{H}_{2} \mathrm{O}(v=0)$ signal intensity was also essentially identical to that shown in Fig. 1(b) for the case of $\mathrm{H}_{2} \mathrm{O}(v=0)$ from ASW.

\section{B. Photodesorption of $\mathrm{D}_{2} \mathrm{O}$ following $157 \mathrm{~nm}$ photoirradiation on $\operatorname{ASW}\left(\mathrm{D}_{2} \mathrm{O}\right)$}

Figure 4(a) shows a rotationally resolved REMPI spectrum of part of the $C-X 0_{0}^{0}$ transition of $\mathrm{D}_{2} \mathrm{O}$ formed by 157 $\mathrm{nm}$ photoirradiation on $\mathrm{ASW}\left(\mathrm{D}_{2} \mathrm{O}\right)$ at $90 \mathrm{~K}$ and $t=2.5 \mu \mathrm{s}$. The best-fit simulation, which assumes $T_{\text {rot }}=350 \pm 150 \mathrm{~K}$ $\left(\left\langle E_{\mathrm{rot}}\right\rangle=4.4 \pm 1.9 \mathrm{~kJ} \mathrm{~mol}^{-1}\right)$ and $g_{\mathrm{OPR}}=2$, is shown in Fig. 4(b). Figure 5(a) shows a TOF spectrum of photodesorbed $\mathrm{D}_{2} \mathrm{O}(v=0)$ molecules measured when exciting the line at $248.057 \mathrm{~nm}$ of the $\mathrm{D}_{2} \mathrm{O}, C-X, 0_{0}^{0}$ band (of which the largest contributor is $3_{12^{-}} 4_{31}$ transition), which is reproduced well by a MB distribution with $T_{\text {trans }}=1800 \pm 500 \mathrm{~K} \quad\left(\left\langle E_{\text {trans }}\right\rangle\right.$ $\left.=29.9 \pm 8.3 \mathrm{~kJ} \mathrm{~mol}^{-1}\right)$. We have also measured TOF spectra for the $\mathrm{D}_{2} \mathrm{O}$ line at $247.525 \mathrm{~nm}$ for which several lines around $J=10$ contribute. This TOF spectrum was similar to that when exciting the line at $248.057 \mathrm{~nm}$ and reproduced well assuming $T_{\text {trans }}=2000 \pm 500 \mathrm{~K} \quad\left(\left\langle E_{\text {trans }}\right\rangle\right.$ $\left.=33.3 \pm 8.3 \mathrm{~kJ} \mathrm{~mol}^{-1}\right)$. Table I summarizes these results.

\section{Photodesorption of $\mathrm{D}_{2} \mathrm{O}$ following $193 \mathrm{~nm}$ photoirradiation of capped $\mathrm{D}_{2} \mathrm{O}: \mathrm{H}_{2} \mathrm{~S}$ mixed ice layers}

$193 \mathrm{~nm}$ irradiation of pure $\mathrm{ASW}\left(\mathrm{H}_{2} \mathrm{O}\right)$ or $\mathrm{ASW}\left(\mathrm{D}_{2} \mathrm{O}\right)$ resulted in no measurable $\mathrm{H}_{2} \mathrm{O}$ or $\mathrm{D}_{2} \mathrm{O}$ REMPI signal. 193 $\mathrm{nm}$ irradiation of $\mathrm{D}_{2} \mathrm{O}: \mathrm{H}_{2} \mathrm{~S}$ mixed ice layer does result in $\mathrm{D}_{2} \mathrm{O}(v=0)$ molecules, however, as illustrated by the TOF spectrum measured when exciting the REMPI line at $247.865 \mathrm{~nm}$ (mainly the $1_{01}-2_{20}$ transition of the $\mathrm{D}_{2} \mathrm{O}$, $C-X, 0_{0}^{0}$ band) as shown in Fig. 5(b). This TOF spectrum is 
TABLE I. Translational and rotational temperatures of photodesorbed $\mathrm{H}_{2} \mathrm{O}(v=0)$ and $\mathrm{D}_{2} \mathrm{O}(v=0)$ from the 157 nm photolysis of ASW at $90 \mathrm{~K}$.

\begin{tabular}{|c|c|c|}
\hline & \multicolumn{2}{|c|}{ Temperatures (wavenumbers) } \\
\hline & Translation & Rotation \\
\hline $\mathrm{H}_{2} \mathrm{O}$ from $\mathrm{H}_{2} \mathrm{O}$ amorphous solid water ${ }^{\mathrm{a}}$ & $1800 \pm 500 \mathrm{~K}\left(2502 \pm 695 \mathrm{~cm}^{-1}\right)$ & $350 \pm 150 \mathrm{~K}\left(243 \pm 104 \mathrm{~cm}^{-1}\right)^{b}$ \\
\hline $\mathrm{D}_{2} \mathrm{O}$ from $\mathrm{D}_{2} \mathrm{O}$ amorphous solid water ${ }^{\mathrm{a}}$ & $1800 \pm 500 \mathrm{~K}\left(2502 \pm 695 \mathrm{~cm}^{-1}\right)$ & $350 \pm 150 \mathrm{~K}\left(243 \pm 104 \mathrm{~cm}^{-1}\right)^{b}$ \\
\hline $\mathrm{D}_{2} \mathrm{O}$ from $\mathrm{D}_{2} \mathrm{O}: \mathrm{H}_{2} \mathrm{~S}$ mixed ice layer ${ }^{\mathrm{c}}$ & $2250 \pm 750 \mathrm{~K}\left(3128 \pm 1043 \mathrm{~cm}^{-1}\right)$ & $\ldots^{\mathrm{d}}$ \\
\hline MD calculation & $1450 \pm 150 \mathrm{~K}\left(2016 \pm 209 \mathrm{~cm}^{-1}\right)$ & $300 \pm 50 \mathrm{~K}\left(209 \pm 35 \mathrm{~cm}^{-1}\right)$ \\
\hline
\end{tabular}

${ }^{\mathrm{a}} 157 \mathrm{~nm}$ photoirradiation.

${ }^{\mathrm{b}}$ From spectra recorded at $t=2.5 \mu \mathrm{s}$.

${ }^{c} 193 \mathrm{~nm}$ photoirradiation.

${ }^{\mathrm{d}}$ Not measured.

reproduced well with $T_{\text {trans }}=2250 \pm 750 \mathrm{~K} \quad\left(\left\langle E_{\text {trans }}\right\rangle\right.$ $\left.=37.4 \pm 12.5 \mathrm{~kJ} \mathrm{~mol}^{-1}\right)$. The formation of these $\mathrm{D}_{2} \mathrm{O}(v=0)$ is assumed to involve initial formation of translationally hot $\mathrm{H}$ atoms by $193 \mathrm{~nm}$ photolysis of $\mathrm{H}_{2} \mathrm{~S}$, which induce the subsequent photodesorption of $\mathrm{D}_{2} \mathrm{O}$ via the kick-out mechanism. The coverage dependence of the REMPI signal intensity was measured as a function of the dose rate in the range of 10-70 L used to deposit the top $\mathrm{D}_{2} \mathrm{O}$ layer. Stronger $\mathrm{D}_{2} \mathrm{O}$ signals were observed for thicker top $\mathrm{D}_{2} \mathrm{O}$ layers presumably because the lower $\mathrm{D}_{2} \mathrm{O}$ exposures did not result in perfectly coverage of the $\mathrm{H}_{2} \mathrm{~S}$ underlayer. The incomplete coverage was previously obtained in the $193 \mathrm{~nm}$ photolysis of $\mathrm{H}_{2} \mathrm{O} / \mathrm{D}_{2} \mathrm{O}$ ice systems, i.e., $30 \mathrm{~L}$ exposure of $\mathrm{H}_{2} \mathrm{O}$ vapor could cover only the top most $\mathrm{D}_{2} \mathrm{O}$ surface layer of the $\operatorname{ASW}\left(\mathrm{D}_{2} \mathrm{O}\right)$ because of the surface roughness. ${ }^{14}$

We were not able to characterize the rotationally resolved REMPI spectrum for the $\mathrm{D}_{2} \mathrm{O}$ molecules as the signal intensity declined steadily during the scan-presumably as a result of depletion of the $\mathrm{H}_{2} \mathrm{~S}$ and thus of $\mathrm{H}$ atoms to induce the kick-out process upon prolonged exposure to $193 \mathrm{~nm}$ irradiation.

\section{MD RESULTS}

Details of the MD results of photodesorption following photoexcitation of water ice are described by Andersson et al. ${ }^{3,31}$ here only details relevant to $\mathrm{H}_{2} \mathrm{O}$ desorption will be presented. Photodissociation of a water ice molecule can

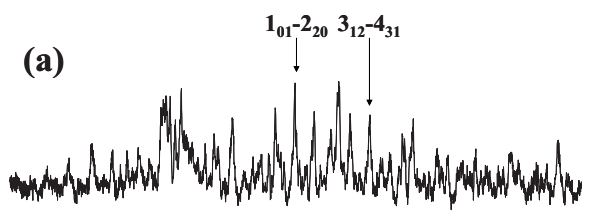

(b)

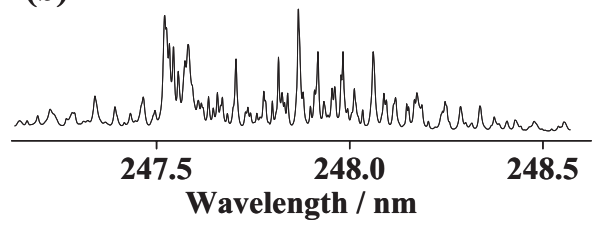

FIG. 4. (a). $2+1$ REMPI spectrum of $\mathrm{D}_{2} \mathrm{O}(v=0)$ formed by the $157 \mathrm{~nm}$ photoirradiation of $\operatorname{ASW}\left(\mathrm{D}_{2} \mathrm{O}\right)$ at $90 \mathrm{~K}$, measured at $t=2.5 \mu \mathrm{s}$. (b). Simulation of the $\mathrm{D}_{2} \mathrm{O}, C-X, 0_{0}^{0}$ two-photon spectrum, assuming a Boltzmann rotational state population distribution with $T_{\text {rot }}=300 \mathrm{~K}$ and $g_{\mathrm{OPR}}=2$. The arrows indicate wavelengths at which TOF spectra were measured for Fig. 5. have several outcomes, with the $\mathrm{H}$ and $\mathrm{OH}$ photoproducts either becoming trapped in the ice, recombining back to a $\mathrm{H}_{2} \mathrm{O}$ molecule, or desorbing from the ice surface. The probability of photodesorption of $\mathrm{H}_{2} \mathrm{O}$ is seen to be low, $1.2 \%$ and $0.8 \%$ per absorbed UV photon in the first and second monolayers, respectively, and then decreases with distance from the surface. Analysis of the trajectories shows that there are two distinct mechanisms for the removal of $\mathrm{H}_{2} \mathrm{O}$ molecules: (a) Kick-out mechanism, an $\mathrm{H}$ atom released from photodissociation of $\mathrm{H}_{2} \mathrm{O}$ is able to transfer enough momentum to one of the other $\mathrm{H}_{2} \mathrm{O}$ molecules to kick it off the surface and (b) $\mathrm{H}+\mathrm{OH}$ recombination mechanism, $\mathrm{H}$ and $\mathrm{OH}$ promptly recombine to form $\mathrm{H}_{2} \mathrm{O}$ and subsequently desorb. In the top two monolayers, both the kick-out and the $\mathrm{H}$ $+\mathrm{OH}$ recombination mechanisms occur with relative probability ratios of one to four. When photoexcitation occurs in

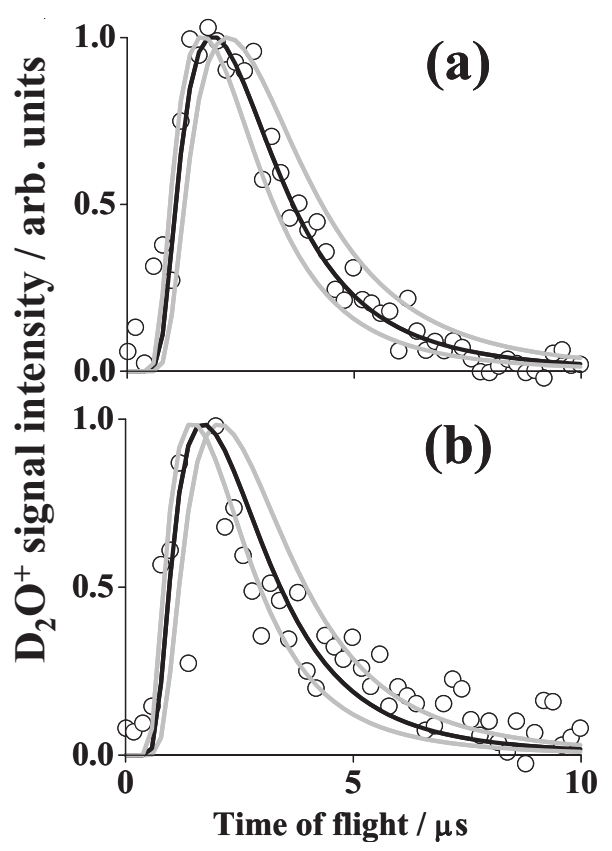

FIG. 5. (a) TOF spectrum of $\mathrm{D}_{2} \mathrm{O}(v=0)$ formed by $157 \mathrm{~nm}$ photoirradiation of $\operatorname{ASW}\left(\mathrm{D}_{2} \mathrm{O}\right)$ at $90 \mathrm{~K}$, monitored by $2+1$ REMPI via the line at 248.057 $\mathrm{nm}$ of the $C-X 0_{0}^{0}$ band. The solid curve is a fit to the data derived assuming $T_{\text {trans }}=1800 \mathrm{~K}$. (b) TOF spectrum of $\mathrm{D}_{2} \mathrm{O}(v=0)$ formed by $193 \mathrm{~nm}$ photoirradiation of the $\mathrm{D}_{2} \mathrm{O}: \mathrm{H}_{2} \mathrm{~S}$ mixed ice sample at $90 \mathrm{~K}$, monitored by $(2+1)$ REMPI via the line at $247.865 \mathrm{~nm}$, which is mainly the $1_{01}-2_{20}$ transition of the $C-X 0_{0}^{0}$ band. The solid curve is a fit to the data derived assuming $T_{\text {trans }}=2250 \mathrm{~K}$. The two gray curves show the range spanned by the error bars quoted in Table I. 
the third monolayer, the total $\mathrm{H}_{2} \mathrm{O}$ desorption probability is $0.4 \%$, and here the kick-out mechanism is dominant, four times more likely than the other mechanism. Because the $\mathrm{H}_{2} \mathrm{O}$ molecules are restricted to be rigid, they are by construct considered to be in their vibrational ground states. The recombination process results in the formation of vibrationally excited $\mathrm{H}_{2} \mathrm{O}$ molecules, with an average rovibrational energy almost exactly equal to the dissociation limit of $\mathrm{H}_{2} \mathrm{O}$. This should be seen as an upper limit, since the present MD model does not allow energy transfer to the vibrational modes of the surrounding molecules. The lowest calculated rovibrational energy is $173.7 \mathrm{~kJ} \mathrm{~mol}^{-1}$ above the zero-point energy level. Thus, there was no evidence of desorption of $\mathrm{H}_{2} \mathrm{O}$ in the vibrational ground state from the recombination mechanism. We could not observe vibrationally excited $\mathrm{H}_{2} \mathrm{O}$ experimentally because of spectroscopic limitations. The calculated average translational and rotational energies of $\mathrm{H}_{2} \mathrm{O}(v=0)$ for the kick-out mechanism is $T_{\text {trans }}$ $=1450 \pm 150 \mathrm{~K} \quad\left(\left\langle E_{\text {trans }}\right\rangle=24.1 \pm 2.9 \mathrm{~kJ} \mathrm{~mol}^{-1}\right)$ and $T_{\text {rot }}$ $=300 \pm 50 \mathrm{~K} \quad\left(\left\langle E_{\mathrm{rot}}\right\rangle=3.7 \pm 0.6 \mathrm{~kJ} \mathrm{~mol}^{-1}\right), \quad$ respectively. These values are in good accord with the experimental values as shown in Table I.

One interesting observation regarding molecules desorbing via the kick-out mechanism is that their translational energies are much higher than the rotational energies. The likely explanation for this is that the $\mathrm{H}$ atom dissociates along the hydrogen bond connecting it to the neighboring $\mathrm{H}_{2} \mathrm{O}$ molecule. It thereby hits the $\mathrm{O}$ atom and not one of the $\mathrm{H}$ atoms, which could lead to (a) reaction or (b) high rotational excitation. Because the $\mathrm{H}$ atom hits the $\mathrm{H}_{2} \mathrm{O}$ molecule close to the center of mass, most of the energy is transferred into translation and much less into rotation. Hitting the $\mathrm{O}$ atom in the $\mathrm{H}_{2} \mathrm{O}$ molecule also gives rise to an intermediate $\mathrm{H}_{3} \mathrm{O}$ configuration that redissociates into $\mathrm{H}$ and $\mathrm{H}_{2} \mathrm{O}$ and not to $\mathrm{H}_{2}+\mathrm{OH}$. In the experiments by Yabushita et al., ${ }^{35,36}$ photodesorbing $\mathrm{H}_{2}$ molecules were observed, which were inferred to be produced from the reaction of $\mathrm{H}$ atoms with $\mathrm{H}_{2} \mathrm{O}$ molecules. Because the $\mathrm{H}_{2} \mathrm{O}$ molecules are restricted to be rigid in the $\mathrm{MD}$ simulations, it is at present not possible to study this reaction.

\section{DISCUSSION}

\section{A. Dependence on water ice morphology}

Yabushita et al. previously investigated the photodissociation dynamics of ASW and PCI by analyzing the TOF spectra of photofragment hydrogen atoms following 157 and $193 \mathrm{~nm}$ photolysis of the water ice. ${ }^{14,15}$ For ASW, the translational energy of most $\mathrm{H}$ atoms was accommodated to the substrate temperature by collisions with bulk water ice before desorption since ASW has a large surface area with micropores. For PCI, on the other hand, the translationally hot $\mathrm{H}$ photofragments could desorb from the surface without losing energy by collisions with PCI. However, the present $\mathrm{H}_{2} \mathrm{O}$ measurements show little difference in signal intensity or TOF profile when using ASW or PCI samples. This observation suggests that any $\mathrm{H}_{2} \mathrm{O}$ molecules that initially desorbed from within the micropores of an ASW sample suffer subsequent collisions with the inside wall of the pore and readsorb strongly - by hydrogen bonding with the low temperature surface. As a result, only the translationally hot TOF component that escapes without energy loss through interactions with the internal surface of the voids, i.e., primarily from the top surface of the ASW sample, is observed. Since the effective surface area of the uppermost part of the irradiated sample will be similar for both PCI and ASW, it follows that the REMPI and TOF spectra and the time evolution of the desorbed signal intensity should be similar for ASW and PCI. Even if hot water molecules are produced deep within the bulk phase, they cannot come out to the vacuum as suggested by the MD calculation. ${ }^{3,31}$ Similar behaviors were observed in desorption of $\mathrm{OH}$ radicals and $\mathrm{O}\left({ }^{1} \mathrm{D}_{2}\right.$ and $\left.{ }^{3} \mathrm{P}_{J}\right)$ atoms following $157 \mathrm{~nm}$ photoirradiation of water ice, i.e., the dominant fraction of $\mathrm{OH}$ and $\mathrm{O}\left({ }^{1} \mathrm{D}_{2}\right.$ and $\left.{ }^{3} \mathrm{P}_{J}\right)$ products desorbed into vacuum is released from the surface of water ice. $^{37-39}$

\section{B. Desorption mechanisms of $\mathrm{H}_{2} \mathrm{O}(v=0)$}

We have previously discussed four possible desorption mechanisms under $157 \mathrm{~nm}$ photoirradiation. ${ }^{16}$

(a) Kick-out mechanism: An $\mathrm{H}$ atom released by photodissociation of $\mathrm{H}_{2} \mathrm{O}$ in the ice transfers enough momentum to another $\mathrm{H}_{2} \mathrm{O}$ molecule to cause its ejection from the ice surface.

(b) $\mathrm{H}+\mathrm{OH}$ recombination mechanism: The recombination of photoproduced $\mathrm{H}$ and $\mathrm{OH}$ species to reform $\mathrm{H}_{2} \mathrm{O}$ is highly exothermic $\left(\Delta H=-497.1 \mathrm{~kJ} \mathrm{~mol}^{-1}\right)$ and sufficient to enable subsequent desorption., ${ }^{3,31}$

(c) Exciton-mediated mechanism: Photodesorption associated with excitons in ASW enables transfer of energy from the bulk to near the ice surface and subsequent loss of molecules from the surface. ${ }^{40,41}$ The lowest energy electronic excitation of $\mathrm{H}_{2} \mathrm{O}$ has a threshold at $\sim 725 \mathrm{~kJ} \mathrm{~mol}^{-1}(\lambda \sim 165 \mathrm{~nm})$.

(d) Reactions of radicals formed by the photodissociation of ice: The accumulation and diffusion of photoproduced radicals in, or on, the ice are necessary for water desorption to occur as proposed by Westley et al. ${ }^{7,8}$

Photodesorption mechanisms (b) and (c) are both highly exothermic and can be expected to yield vibrationally hot water molecules. As such, we consider them to be unlikely sources for the $\mathrm{H}_{2} \mathrm{O}(v=0)$ ejection observed in the present experiments. Furthermore, Fig. 1(b) shows that the $\mathrm{H}_{2} \mathrm{O}(v$ $=0)$ desorption from $\operatorname{ASW}\left(\mathrm{H}_{2} \mathrm{O}\right)$ appears promptly after 157 $\mathrm{nm}$ irradiation starts, and the desorption yield is independent of $157 \mathrm{~nm}$ irradiation time, i.e., the desorption appears to occur without any initial accumulation of photoproduct radicals on the ice surface; hence, mechanism (d) also seems inappropriate. Thus the main photodesorption mechanism for forming $\mathrm{H}_{2} \mathrm{O}(v=0)$ products under the present experimental conditions is likely to be the kick-out mechanism (a), i.e., reaction sequences (1) and (2). Hereafter we concentrate discussion on this kick-out mechanism. 


\section{1. $\mathrm{H}_{2} \mathrm{O}$ signal intensity change as a function of 157 nm photoirradiation time}

The kick-out mechanism can explain the results shown in Fig. 1(b) since the hot $\mathrm{H}$ atom is immediately produced after $157 \mathrm{~nm}$ photodissociation of ASW and the concentration of hot $\mathrm{H}$ atoms should be stable on/in ASW after each $157 \mathrm{~nm}$ laser pulse. Yabushita et al. previously observed that the majority of hot $\mathrm{H}$ atoms produced by $157 \mathrm{~nm}$ photolysis are accommodated by collisions with the ASW sample. ${ }^{14,15}$ The subsequent formation of $\mathrm{H}_{2}$ products via a hydrogen abstraction reaction was also observed with the same experimental setup. ${ }^{35,36} \mathrm{H}_{2}$ formation by reaction sequence (1)-(5) is an endothermic process, and the activation energy for reaction (5) is estimated to be $132.8 \mathrm{~kJ} \mathrm{~mol}^{-1}$ from the corresponding gas-phase reaction, ${ }^{42}$ but the reaction can proceed by virtue of the translational excitation of the hot $\mathrm{H}$ atoms formed in the photolysis reaction (1), $15,35,36$

$$
\text { hot } \mathrm{H}+\mathrm{H}_{2} \mathrm{O}(\mathrm{ads}) \rightarrow \mathrm{OH}+\mathrm{H}_{2}, \begin{array}{ll}
\Delta H\left(\mathrm{~kJ} \mathrm{~mol}^{-1}\right) \\
107.3 .
\end{array}
$$

Since the kick-out process (a), i.e., reactions (1) and (2), is less endothermic than $\mathrm{H}_{2}$ formation by reaction sequence (1)-(5), the $\mathrm{H}_{2} \mathrm{O}$ molecules hit by $\mathrm{H}$ atoms on the ice surface are likely to be desorbed into vacuum.

In contrast, the $\mathrm{H}+\mathrm{OH}$ recombination process and the reaction of radicals formed by the photodissociation of ice, mechanisms (b) and (d), both depend on radical accumulation at the surface, and their increasing concentration with irradiation time should thus reveal itself by a progressive increase in desorption rate. Indeed, such behavior has been observed for both $\mathrm{OH}$ radicals and $\mathrm{O}$ atoms that photodesorb via reactions involving radicals. ${ }^{37-39}$ The results shown in Fig. 1(b) thus suggest that mechanisms (b) and (d) are unlikely to be major sources for desorbed $\mathrm{H}_{2} \mathrm{O}(v=0)$ molecules.

\section{2. $193 \mathrm{~nm}$ photoirradiation experiments for $\mathrm{D}_{2} \mathrm{O}: \mathrm{H}_{2} \mathrm{~S}$ mixed ice}

The results of the $193 \mathrm{~nm}$ photolysis of the $\mathrm{D}_{2} \mathrm{O}: \mathrm{H}_{2} \mathrm{~S}$ mixed ice layers provides further evidence in support of the kick-out mechanism, i.e., reaction (2). The available energy following $\mathrm{S}-\mathrm{H}$ bond fission in the gas-phase photolysis of $\mathrm{H}_{2} \mathrm{~S}$ at $193 \mathrm{~nm}$ is $E_{\text {avail }}=238.4 \mathrm{~kJ} \mathrm{~mol}^{-1} .{ }^{13}$ Khriachtchev $e t$ $a l .{ }^{43}$ investigated the $193 \mathrm{~nm}$ photolysis of $\mathrm{H}_{2} \mathrm{~S}$ in solid raregas matrices and deduced that (as in the gas phase) this excess energy is largely channeled into $\mathrm{H}$ atom translational energy.

$\mathrm{H}_{2} \mathrm{O}$ or $\mathrm{D}_{2} \mathrm{O}$ REMPI signals were not observed in the $193 \mathrm{~nm}$ laser irradiation of neat $\mathrm{ASW}\left(\mathrm{H}_{2} \mathrm{O}\right)$ or $\operatorname{ASW}\left(\mathrm{D}_{2} \mathrm{O}\right)$ consistent with the negligible absorption cross-section of bulk ice at this wavelength. H(D) atoms are formed however, but these are attributed to $193 \mathrm{~nm}$ photodissociation of dimerlike $\mathrm{H}_{2} \mathrm{O}$ or $\mathrm{D}_{2} \mathrm{O}$ structures located at the ice/vacuum interface. ${ }^{14,15,44}$ Given that they originate from loosely surface-bound species, it is much less likely for such $\mathrm{H}$ atoms to induce secondary reactions with neighboring atoms or molecules. Substrate-mediated photodesorption due to the temporary attachment of photo-electrons from the Au sub- strate is not considered to be a viable mechanism for the present photodesorption of water molecules from the ice surface. $^{10,22}$

\section{Other desorption mechanisms for possible formation of $\mathrm{H}_{2} \mathrm{O}(v \geq 1)$}

The present work strongly suggests that kick-out is the dominant desorption mechanism for $\mathrm{H}_{2} \mathrm{O}(v=0)$ and $\mathrm{D}_{2} \mathrm{O}(v=0)$ molecules following $157 \mathrm{~nm}$ photodesorption of ice at $90 \mathrm{~K}$. The present experiments do not exclude the possible formation of vibrationally excited water molecules, however. As argued above, vibrationally excited $\mathrm{H}_{2} \mathrm{O}$ molecules might be expected from alternative desorption mechanisms, e.g., the $\mathrm{H}$ and $\mathrm{OH}$ recombination process (b), or an exciton mediated process (c). We tried to search for REMPI signals of $\mathrm{H}_{2} \mathrm{O}(v \geq 1)$, but no evidence for $\mathrm{H}_{2} \mathrm{O}(v \geq 1)$ products was obtained, most likely reflecting the limitations of the spectroscopy used. Hence, the other desorption mechanisms will be briefly discussed in the context of possible photodesorption of vibrationally excited $\mathrm{H}_{2} \mathrm{O}\left(\mathrm{D}_{2} \mathrm{O}\right)$ molecules.

\section{1. $\mathrm{H}$ and $\mathrm{OH}$ recombination process}

The MD calculations suggest that $\mathrm{H}$ atoms could also recombine with $\mathrm{OH}$ radicals, and the resulting $\mathrm{H}_{2} \mathrm{O}$ molecule subsequent desorb as the recombination is highly exothermic. ${ }^{3,31}$ The vuv photolysis studies of Yabushita et al. ${ }^{35,36}$ deduced that $\mathrm{H}_{2}$ formation at a water ice surface at $90 \mathrm{~K}$ was attributable to the highly exothermic recombination of photolytically produced $\mathrm{H}$ atoms. $\mathrm{H}_{2} \mathrm{O}_{2}$ formation on a water ice surface has also been observed ${ }^{45}$ presumably from the recombination of photolytically produced $\mathrm{OH}$ radicals. These results serve to encourage the view that photoirradiation leads to desorption of $\mathrm{H}_{2} \mathrm{O}$ molecules in excited vibrational levels via the $\mathrm{H}+\mathrm{OH}$ recombination mechanism.

\section{An exciton-mediated process}

The optical depth of ASW at $157 \mathrm{~nm}$ is $\sim 100 \mathrm{~nm},{ }^{41}$ so the photon energy available for reaction is primarily absorbed in the bulk of the water ice. A qualitative depiction of the band structure of ice has been reported by Kimmel et $a l .{ }^{46}$ Excitons associated with the $4 \mathrm{a}_{1}{ }^{*} \leftarrow 1 \mathrm{~b}_{1}$ transition in condensed water have been implicated in a low-energy electron stimulated reaction, which could enable transfer of energy from the bulk to near the ASW surface. ${ }^{40,41}$ Kimmel and co-workers found experimental support for the concept of mobile excitons in ASW that initiate reactions at the ASW/ vacuum interface. ${ }^{20,21,47,48}$ Significant vibrational excitation might be anticipated if the excess energy from the electronic excitation was deposited into an $\mathrm{H}_{2} \mathrm{O}$ molecule that desorbed as a result of such a mechanism.

\section{SUMMARY}

The translational and rotational energies of water molecules $\left(\mathrm{H}_{2} \mathrm{O}\right.$ and $\mathrm{D}_{2} \mathrm{O}$, in their ground vibrational state) desorbed following $157 \mathrm{~nm}$ excitation of amorphous solid water and polycrystalline ice have been measured. The measured energy distributions are in good accord with those 
predicted by classical molecular dynamics calculations for the kick-out mechanism, i.e., the ejection of a water molecule from the ice surface by a hot hydrogen (deuterium) atom formed by photodissociation of a neighboring water molecule. Desorption of $\mathrm{D}_{2} \mathrm{O}$ following $193 \mathrm{~nm}$ photoirradiation of a $\mathrm{D}_{2} \mathrm{O} / \mathrm{H}_{2} \mathrm{~S}$ mixed ice was investigated also for additional direct evidence of the operation of the kick-out mechanism. The ortho:para ratios of the photodesorbed $\mathrm{H}_{2} \mathrm{O}$ and $\mathrm{D}_{2} \mathrm{O}$ products $(3: 1$ and $2: 1$, respectively) are appropriate for the measured Boltzmann rotational distributions.

\section{ACKNOWLEDGMENTS}

This work was supported by a grant-in-aid from JSPS (Grant No. 20245005). M.K. and M.N.R.A continue to be most grateful to the Daiwa Anglo-Japanese Foundation for the award of a Daiwa-Adrian Prize that facilitated earlier phases of this collaboration.

${ }^{1}$ C. Dominik, C. Ceccarelli, D. Hollenbach, and M. Kaufman, Astrophys. J. 635, L85 (2005).

${ }^{2}$ D. Hollenbach, M. J. Kaufman, E. A. Bergin, and G. J. Melnick, Astrophys. J. 690, 1497 (2009).

${ }^{3}$ S. Andersson and E. F. van Dishoeck, Astron. Astrophys. 491, 907 (2008).

${ }^{4}$ C. Shen, J. M. Greenberg, W. A. Schutte, and E. F. van Dishoeck, Astron. Astrophys. 415, 203 (2004).

${ }^{5}$ J. D. Thrower, D. J. Burke, M. P. Collings, A. Dawes, P. D. Holtom, F. Jamme, P. Kendall, W. A. Brown, I. P. Clark, H. J. Fraser, M. R. S. McCoustra, N. J. Mason, and A. W. Parker, Astrophys. J. 673, 1233 (2008).

${ }^{6}$ J. D. Thrower, M. P. Collings, M. R. S. McCoustra, D. J. Burke, W. A. Brown, A. Dawes, P. D. Holtom, P. Kendall, N. J. Mason, F. Jamme, H. J. Fraser, I. P. Clark, and A. W. Parker, J. Vac. Sci. Technol. A 26, 919 (2008)

${ }^{7}$ M. S. Westley, R. A. Baragiola, R. E. Johnson, and G. A. Baratta, Nature (London) 373, 405 (1995).

${ }^{8}$ M. S. Westley, R. A. Baragiola, R. E. Johnson, and G. A. Baratta, Planet. Space Sci. 43, 1311 (1995).

${ }^{9}$ J. Bergeld and D. Chakarov, J. Chem. Phys. 125, 141103 (2006).

${ }^{10}$ M. Wolf, S. Nettesheim, J. M. White, E. Hasselbrink, and G. Ertl, J. Chem. Phys. 94, 4609 (1991).

${ }^{11}$ K. I. Öberg, H. Linnartz, R. Visser, and E. F. van Dishoeck, Astrophys. J. 693, 1209 (2009).

${ }^{12}$ M. Kh. Karapet'yants and M. K. Karapet'yants, Handbook of Thermodynamic Constants of Inorganic and Organic Compounds (Ann ArborHumphrey Science, London, 1970).

${ }^{13}$ S. P. Sander, B. J. Finlayson-Pitts, R. R. Friedl, D. M. Golden, R. E. Huie, H. Keller-Rudek, C. E. Kolb, M. J. Kurylo, M. J. Molina, G. K. Moortgat, V. L. Orkin, A. R. Ravishankara, and P. H. Wine, "Chemical kinetics and photochemical data for use in atmospheric studies, evaluation number 15," JPL Publication 06-2, Jet Propulsion Laboratory, Pasadena, 2006.

${ }^{14}$ A. Yabushita, Y. Hashikawa, A. Ikeda, M. Kawasaki, and H. Tachikawa, J. Chem. Phys. 120, 5463 (2004).

${ }^{15}$ A. Yabushita, D. Kanda, N. Kawanaka, M. Kawasaki, and M. N. R.
Ashfold, J. Chem. Phys. 125, 133406 (2006).

${ }^{16}$ A. Yabushita, T. Hama, M. Yokoyama, M. Kawasaki, S. Andersson, R. N. Dixon, M. N. R. Ashfold, and N. Watanabe, Astrophys. J. 699, L80 (2009).

${ }^{17}$ A. Yabushita, Y. Inoue, T. Senga, M. Kawasaki, and S. Sato, J. Phys. Chem. B 106, 3151 (2002).

${ }^{18}$ M. Kawasaki, Appl. Surf. Sci. 135, 115 (1998).

${ }^{19}$ S. Sato, D. Yamaguchi, K. Nakagawa, Y. Inoue, A. Yabushita, and M. Kawasaki, Langmuir 16, 9533 (2000).

${ }^{20}$ N. G. Petrik and G. A. Kimmel, J. Phys. Chem. C 113, 4451 (2009).

${ }^{21}$ N. G. Petrik, A. G. Kavetsky, and G. A. Kimmel, J. Chem. Phys. 125, 124702 (2006).

${ }^{22}$ E. H. G. Backus, M. L. Grecea, A. W. Kleyn, and M. Bonn, J. Phys. Chem. B 111, 6141 (2007).

${ }^{23} \mathrm{C}$. M. Western, PGOPHER, a program for simulating rotational structure, University of Bristol, available at http://pgopher.chm.bris.ac.uk.

${ }^{24}$ M. N. R. Ashfold, J. M. Bayley, R. N. Dixon, and J. D. Prince, Ber. Bunsenges. Phys. Chem. 89, 254 (1985), and references therein.

${ }^{25}$ B. W. Uselman, J. M. Boyle, and S. L. Anderson, Chem. Phys. Lett. 440, 171 (2007).

${ }^{26}$ B. P. Bonev, M. J. Mumma, G. L. Villanueva, M. A. Disanti, R. S. Ellis, K. Magee-Sauer, and N. Dello Russo, Astrophys. J. 661, L97 (2007).

${ }^{27}$ F. M. Zimmermann and W. Ho, J. Chem. Phys. 100, 7700 (1994).

${ }^{28}$ F. M. Zimmermann and W. Ho, Surf. Sci. Rep. 22, 127 (1995).

${ }^{29}$ A. Yabushita, Y. Inoue, T. Senga, M. Kawasaki, and S. Sato, J. Phys. Chem. A 108, 438 (2004).

${ }^{30}$ M. P. Allen and D. J. Tildesley, Computer Simulations of Liquids (Clarendon, Oxford, 1987).

${ }^{31}$ S. Andersson, A. Al-Halabi, G.-J. Kroes, and E. F. van Dishoeck, J. Chem. Phys. 124, 064715 (2006).

${ }^{32}$ A. Al-Halabi, E. F. van Dishoeck, and G. J. Kroes, J. Chem. Phys. 120, 3358 (2004).

${ }^{33}$ A. Al-Halabi, H. F. Fraser, G. J. Kroes, and E. F. van Dishoeck, Astron. Astrophys. 422, 777 (2004).

${ }^{34}$ A. J. Dobbyn and P. J. Knowles, Mol. Phys. 91, 1107 (1997).

${ }^{35}$ A. Yabushita, T. Hama, D. Iida, N. Kawanaka, M. Kawasaki, N. Watanabe, M. N. R. Ashfold, and H.-P. Loock, Astrophys. J. 682, L69 (2008).

${ }^{36}$ A. Yabushita, T. Hama, D. Iida, N. Kawanaka, M. Kawasaki, N. Watanabe, M. N. R. Ashfold, and H.-P. Loock, J. Chem. Phys. 129, 044501 (2008).

${ }^{37}$ T. Hama, A. Yabushita, M. Yokoyama, M. Kawasaki, and S. Andersson, J. Chem. Phys. 131, 054508 (2009).

${ }^{38}$ T. Hama, A. Yabushita, M. Yokoyama, M. Kawasaki, and N. Watanabe, J. Chem. Phys. 131, 114510 (2009).

${ }^{39}$ T. Hama, A. Yabushita, M. Yokoyama, M. Kawasaki, and N. Watanabe, J. Chem. Phys. 131, 114511 (2009).

${ }^{40}$ T. M. Orlando and G. A. Kimmel, Surf. Sci. 390, 79 (1997).

${ }^{41}$ K. Kobayashi, J. Phys. Chem. 87, 4317 (1983).

${ }^{42}$ D. H. Zhang and J. C. Light, J. Chem. Phys. 104, 4544 (1996).

${ }^{43}$ L. Khriachtchev, M. Pettersson, E. Isoniemi, and M. Räsänen, J. Chem. Phys. 108, 5747 (1998).

${ }^{44}$ G. Avila, G. J. Kroes, and M. C. van Hemert, J. Chem. Phys. 128, 144313 (2008).

${ }^{45}$ A. Yabushita, T. Hama, D. Iida, and M. Kawasaki, J. Chem. Phys. 129, 014709 (2008).

${ }^{46}$ G. A. Kimmel, T. M. Orlando, C. Vezina, and L. Sanche, J. Chem. Phys. 101, 3282 (1994).

${ }^{47}$ N. G. Petrik and G. A. Kimmel, Phys. Rev. Lett. 90, 166102 (2003).

${ }^{48}$ N. G. Petrik and G. A. Kimmel, J. Chem. Phys. 121, 3736 (2004). 